Article

\title{
TechTeach-An Innovative Method to Increase the Students Engagement at Classrooms ${ }^{\dagger}$
}

\author{
Filipe Portela ${ }^{1,2}$ (D) \\ 1 Algoritmi Research Centre, University of Minho, 4800-058 Guimarães, Portugal; cfp@dsi.uminho.pt \\ 2 IOTECH-Innovation on Technology, 4785-588 Trofa, Portugal \\ $+\quad$ This paper is an extended version of our paper published in ICPEC 2020.
}

Received: 25 September 2020; Accepted: 11 October 2020; Published: 14 October 2020

check for updates

\begin{abstract}
Higher education is changing, and a new normal is coming. Students are even more demanding, and professors need to follow the evolution of technology and try to increase student engagement in the classrooms (presential or virtual). Higher education students recognise that the introduction of new tools and learning methods can improve the teaching quality and increase the motivation to learn. Regarding a question about which type of classes students preferred, ninety-one point ninety-nine per cent $(91.99 \%)$ of the students wanted interactive classes over traditional. Having this concern in mind over the past years, a professor explored a set of methods, strategies and tools and designed a new and innovative paradigm using gamification. This approach is denominated TechTeach and explores a set of trending concepts and interactive tools to teach computer science subjects. It was designed to run in a B-learning environment. The paradigm uses flipped classrooms, bring your own device (BYOD), gamification, training of soft-skills and quizzes and surveys to increase the student's engagement and provide the best learning environment to students. Currently, COVID-19 is bringing about new challenges, and TechTeach was improved in order to be more suitable for this new way of teaching (from $0 \%$ to $100 \%$ online classes). This article details this method and shows how it can be applied in a real environment. A case study was used to prove the functionality and relevance of this approach, and the achieved results are motivating. During the semester, more than a hundred students experienced this new way of teaching and assessment. In the end, more than eighty-one per cent $(81 \%)$ of the students gave a positive grade to the approach, and more than ninety-five per cent $(95.65 \%)$ of the students approved the use of the concept of BYOD in the classroom. With TechTeach, the classroom is not a boring place anymore; it is a place to learn and enjoy regardless of being physical or not.
\end{abstract}

Keywords: bring your own device (BYOD); gamification; TechTeach; classrooms; computer science; students engagement; B-learning; flipped flassrooms

\section{Introduction}

Learning environments and methods are continually changing. These changes are even more prolific than usual in the computer science area. New courses and coding languages arise every day, and in consequence, it becomes harder to motivate a student. The numbers of distractions and different ways of obtaining knowledge are enormous. The professor needs to find new methods to bring students to his class and increase their engagement. COVID19 represents the maximum realisation of this new reality. It brings new challenges to society, and everyone is facing several difficulties. Professors and students were not prepared for a different way of learning (e.g., without presential contact). Thus, this adaptation was an ongoing learning process.

This new reality proves that it is time to change the traditional paradigm. A professor cannot be a person who only teaches but must be someone who explores new trends, ideas and concepts, 
and motivates the students to learn. The use of flexibility, technology and innovation during the teaching process can lead to challenging learning environments [1] and even increase motivation. According to Araújo, C [2], "Education, as it is, based on a model of skills, constitutes the development of utilitarian, stratified knowledge, that overvalues preparation for the labour market overtraining for the employment world, in its ontological value". The learning environments are being transformed into flexible spaces that can be located within or outside the institution [1]. Recent technological developments have given rise to blended learning classrooms [1] that can be motivated by the use of gamification. This concept has recently generated increased attention across a range of contexts [3], such as education. One of the most relevant changes occurred with the implementation of the Bologna model [2]. The primary adjustment went through the development and the acquisition of general and specific skills, according to what professional profiles in the labour market determined [2].

Some Universities presented some resistance in changing to the Bologna model [2]. After understanding the real benefits, they followed the proposed model by favouring in their curricula the development and the acquisition of general and specific skills, according to what professional profiles in the labour market determine [2].

The way of teaching is changing, and students are less comprehensive in relation to traditional school. Bologna brings a different approach to education; however, few mindsets changed. It is time to join a set of ideas as it is to define a new approach to teaching in computer science areas.

According to Maria Gonzales et al. [4], "Current education requires a profound process of transformation that must be supported by two fundamental pillars: On the one hand, the information and communication technologies, and on the other, the innovative methodologies that have emerged because of the implementation of the former in the future of teaching".

Regarding this changing, several new studies are arising focusing on flipped learning [4,5], project-based learning [5,6], soft-skills [7,8] or gamification [4,9]. Besides that, a sentence provided by the TPACK framework [10] is too real nowadays: "The TPACK framework for teacher knowledge is described in detail, as a complex interaction among three bodies of knowledge: Content, pedagogy, and technology". The study developed during this work can prove that the interaction of these three bodies of knowledge, combined with theoretical and practices exercises, produced the types of flexible knowledge needed to successfully integrate TechTeach into teaching [10].

Since 2017, more than two hundred (287) students have been questioned on whether they prefer the traditional or the interactive way of teaching. The vast majority of students $(91.99 \%)$ admitted to preferring the interactive classes over the traditional classes. Since then, several methods were made and some technologies were tested. Having in mind the received feedback, in 2019/2020 a new concept emerged. To overcome some of the difficulties found, and to increase students' motivation, a new paradigm of teaching was launched-TechTeach. It compiles the best methods and strategies used over the years. This new concept allows the creation of a B-learning environment and uses gamification to motivate the students to participate in the class. It combines a set of concepts, including B-learning, BYOD, flipped and interactive classes, quizzes and surveys, soft-skills development, active learning and project base-learning. TechTeach was boosted by the development of some new tools able to answer the challenges: ioEduc, ioQuiz and ioChat. This is a clear example of how information systems and new technologies can contribute to the reengineering of processes and digital transformation. It is much more than just an approach-it proves what universities can do for society.

This new paradigm has the goal of increasing the engagement of students in a curricular unit (CUnit) by making it more attractive and interactive. This new paradigm was tested before the pandemic era-the students of "Web Programming" at the University of Minho proved the efficiency of this new approach during the first semester of 2019/2020. After assessing this experience, the results were encouraging: Eighty-one per cent $(81 \%)$ positive answers regarding the adopted strategy and more than eighty-five per cent (85\%) participation at the classroom. Posteriorly, and having in mind the pandemic reality and some new findings, a set of further improvements was made. 
This article is an extended version of the paper [11] and brings fresh air to this theme, aspiring to contribute to the transformation of learning/teaching processes. It dissects TechTeach and presents a new paradigm of learning/teaching at higher education, explaining the transition of the teaching activity to a non-presential environment.

The article is divided into six sections: after a brief introduction of the work, a set of crucial thematics is introduced. Section 3 demonstrates the methods inherent to TechTeach and the materials used to design this new paradigm. Section 4 presents the case study and explains how it can be applied in a real environment. Lastly, Sections 5 and 6 are responsible for discussing the results and ending the article.

\section{Background}

The approach presented in this article involves a set of concepts that are important to explain. The following sections introduce all the subjects inherent to TechTeach.

\subsection{Bologna Process}

The Bologna Process was signed in 1999 [2] and became the reality of the European educational settings [12]. The goal of this declaration is to create a teaching system easily readable with comparable degrees, by allowing promotion of the European dimension in higher education [12]. It is time to follow European directories and promote teaching from the qualification speech to the skills addressed [2]. In a global world, Bologna required changes and a new investment in life-long learning and skills. The concept is simple: The teaching focus is not the professor but the students and their learning capacities. Bologna can promote a different type of teaching that involves [13]:

- Helping students to realise that they can play an active and self-directive role in their learning.

- A gradual shifting of decision making from the teacher to learners and thus a better learner involvement in the learning process itself.

Utilising an analogy from the teaching of languages (idioms), and considering the alterations done in those areas, the shift of decision making from the teacher to the learner can operate at different levels of learning. It can change from basic coding activities and exploration activities to project work involving teamwork, and gathering and shifting of learning materials in the target coding language [14].

\subsection{Blended Learning}

The environment of teaching is changing, and blended learning (B-learning) in higher education is considered a new normal [15]. B-learning is commonly defined as a system that consists of "the thoughtful integration of classroom face-to-face learning experiences with online learning experiences" [16]. A recent study shows that B-learning has several contexts [17] and multiple usages, such as face-to-face learning and online learning combining different instructional methods, pedagogical approaches or technologies. However, these blends are not aligned with the most influential blended learning definitions [17]. Table 1 represents a distribution of online content regarding the different learning and teaching environments. In their classification, Allen et al. [18] defined blended learning with a range from $30 \%$ to $79 \%$ of the content that is delivered online, using online discussions in addition to some face-to-face meetings.

According to Carter [19], higher education institutions with blended learning provide both face-to-face and online courses within the same program. The learners can choose from a mix of the offered courses through different delivery modalities. However, this is not advisable: Each piece of learning content should be unique and adequate to the type of teaching method. This fact requires a profound change in teaching, and fortunately, several new tools are arising [15]. These changes make the students and professors face a fast and autonomous learning process. One of these tools is ioEduc [20], a web/mobile platform that applies the concept of bring your own device (BYOD) in the classrooms. 
Table 1. Classifications of blended learning retrieved from [18].

\begin{tabular}{lll}
\hline Content Delivered Online & Type of Course & \multicolumn{1}{c}{ Typical Description } \\
\hline $0 \%$ & Traditional & $\begin{array}{l}\text { A course with no online technology used-the content } \\
\text { is delivered written or orally. }\end{array}$ \\
& Web Facilitated & $\begin{array}{l}\text { A course that uses a Web-based technology to facilitate } \\
\text { what is essential in a face-to-face course. It uses a course } \\
\text { management system (CMS) or Web pages to post the } \\
\text { syllabus and assignments, for example }\end{array}$ \\
& Blended & $\begin{array}{l}\text { A course that blends online and face-to-face delivery. } \\
\text { The main proportion of the content is delivered online, } \\
\text { typically uses online discussions, having some face-to } \\
\text { face meetings. }\end{array}$ \\
& Online & $\begin{array}{l}\text { A course where most or all the content is delivered } \\
\text { online. Generally it does not have face-to-face meetings. }\end{array}$ \\
\hline
\end{tabular}

\subsection{Bring Your Own Device}

According to Moreira et al. [21], bring your own device (BYOD) is a subset of the consumerisation of information technologies (IT) as private or personally owned IT resources, such as computers or software that are used for business proposes. In the case of education, BYOD consists of bringing laptops, smartphones or other devices to the classroom in order to increase active learning. Unfortunately, most universities still deliver instructions based on the philosophy of a teacher-controlled learning model that promotes passive learning [22]. Using this concept in the classrooms, a set of interesting indicators can be collected (e.g., studying the impact of the system's access with the final grade) [21]. TechTeach wants to show a different way of fostering active learners.

\subsection{Flipped Learning}

Flipped learning or inverted classrooms is a field of B-learning. It is recognised as being an emerging instructional approach that can be used to support the pedagogy of teaching [22]. Learning environments can be any space where the students can learn, and not just a classroom where learning is promoted [1]. Figure 1 shows the main difference between traditional and flipped classrooms-what is done in the classroom or at home (what is done first, teach or study?).

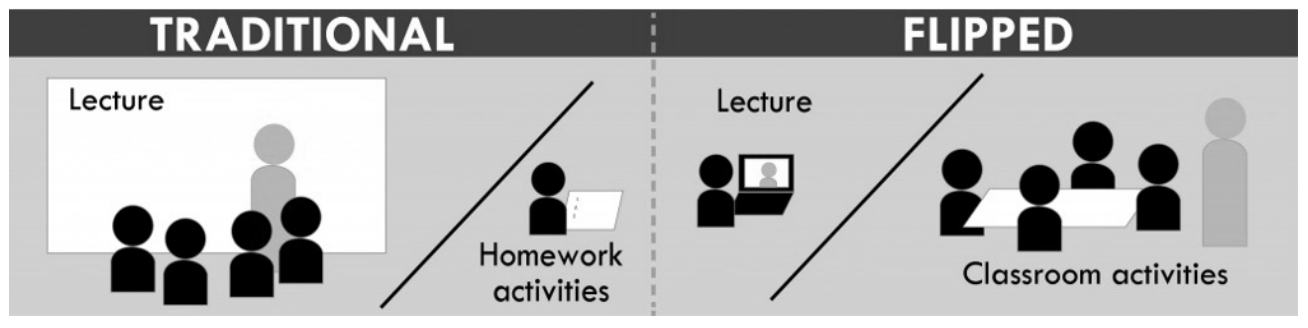

Figure 1. Main difference between traditional and flipped methods. Retrieved from [23].

A flipped classroom consists of using technology to push lectures outside the school. The learning activities will be used to practice the concepts inside the classroom [24]. In a traditional class, a lecturer exposes the topics, and then, the students have to do homework activities. In the flipped environment, students need to study and prepare for the lesson first. They will practice the content of the week's in-classroom activities with the professor and colleagues. 


\subsection{Gamification}

Gamification consists of "using game-based mechanics, aesthetics and game thinking to engage people, motivate action, promote learning, and solve problems" [25]. A past study [22] showed that there are several vital points which guide the deployment of the online gamified learning intervention. Another study [22] demonstrated that online gamified learning activities have a positive impact on the learning outcome.

The use of gamification in education is increasing, as can be observed in two past studies [26,27]. This new reality is a consequence of game-based learning (GBL) which is undergoing a rapid shift to mobile platforms and creating a new type of learning known as mobile-learning (m-learning) [26]. This is an excellent "tool" to motivate people and increase engagement, so it is the primary base of TechTeach.

\subsection{Skills}

The achievement of skills is a natural process of human being development [2]. The constant variations in the modern world require more flexibility and more vital adapting skills [12]. In this field, it is essential to mention that "the concept of skills is also developed in the educational scope and has enunciated alterations of epistemological order which elevate the cognitive and constructivist pedagogical perspective in detriment of behaviourism, raising changes in educational objectives and pedagogical projects since the decade of 1980, relegating the conception of the school curriculum based on the transmission of knowledge to a secondary place and prioritising the building of knowledge" [2].

\subsection{Related Works}

From the literature review, it is possible to find several methodologies, techniques and approaches regarding this thematic. Researchers can easily find some studies/works about these topics, such as the Technological pedagogical content knowledge [10,28], Active and emerging methodologies for ubiquitous education: Potentials of flipped learning and gamification [4], Ubiquitous game-based learning in higher education [9], Flipped classroom and problem-based-learning in higher education [5] and Assessing soft skills of undergraduate students [7,8]. However, in order to have a deep analysis of it, it is essential to develop a benchmarking analysis. This analysis will be the target of a future study.

Regarding this proposed approach, and after reading some of the existing works already mentioned, it is possible to observe that TechTeach is different. Most of the current works use a reduced set of tools/methods to achieve particular goals-for example, flipped classes, project based learning or gamification. TechTeach is much more than that and wants to be a global solution able to group several approaches/methods in one. TeachTeach is not a natural alternative for the existing methods but a different approach, able to combine different experiences in one integrated solution. In this case, the innovation is not doing something new but reinventing what already exists.

\section{Material and Methods}

The methodology is based on a few number of concepts (BYOD, soft-skills, B-learning and gamification) and a set of methods/tasks, as it can be observed in the Figure 2. It is designed for courses with more than six European Credit Transfer and Accumulation System (ECTs) that have theoretical and practical classes. 


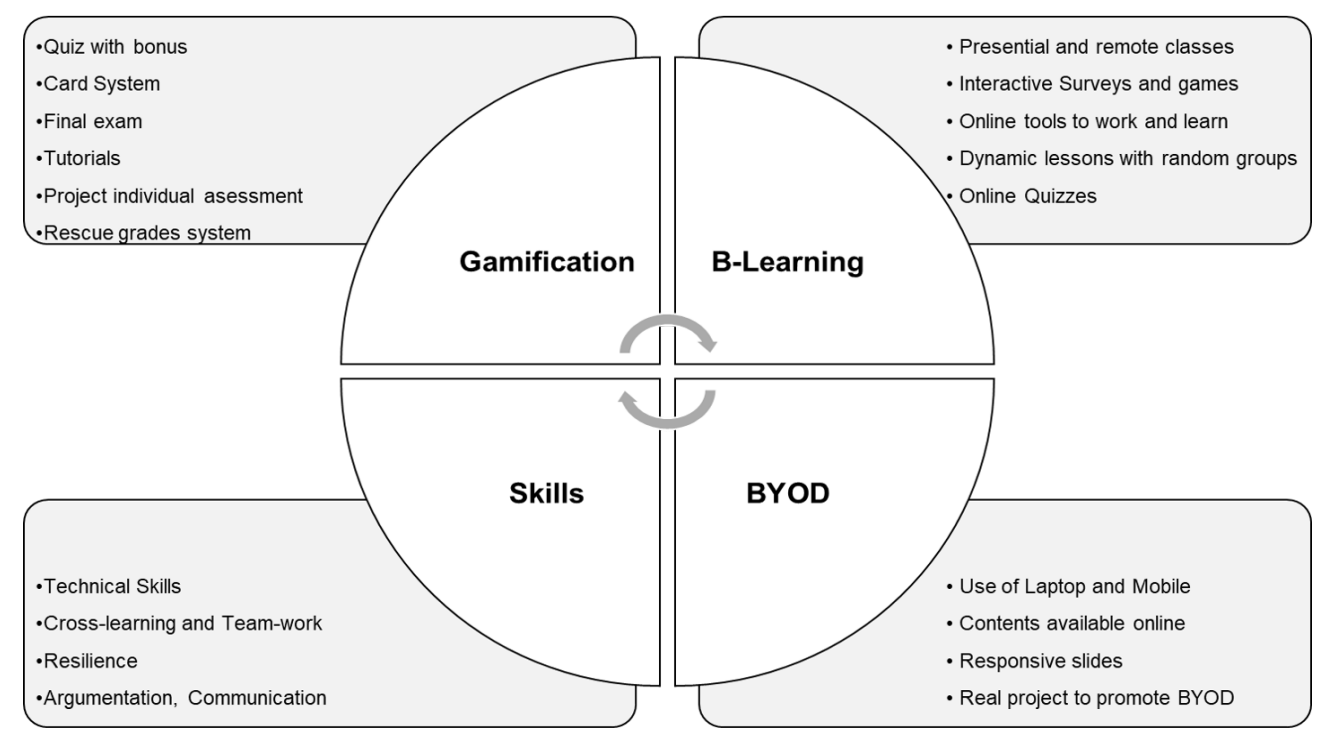

Figure 2. Main concepts of the method.

\subsection{Blended-Learning}

B-learning is the base of this method. The goal is to create two types of learning environments: Presential and non-presential.

1. Presential: Face-to-face and collaborative learning, computer-supported;

2. Non-Presential: Virtual connection, individual and collaborative learning.

Both environments use the BYOD concept to promote active learning and stimulate student engagement during the classes. In addition, the CUnit uses project-based learning (PBL) to stimulate soft-skills and approximate the learning to the professional market. To classify the type of a CUnit, and to see how it can be improved in order to be prepared for B-learning, professors should use the EMBED self-assessment tool (https:/ / embed.eadtu.eu) and ABC toolkit-Thinking tool from the University of Auckland (https:/ / flexiblelearning.auckland.ac.nz/abc/toolkit.html). EMBED is a tool that can be used to self-assess the maturity of blended education in a course, programme or institution. The maturity level ranges from zero (0) to three (3) regarding the following aspects:

- Course design Process: Sequence of activities;

- Course design process: Selection blended learning tools;

- Course flexibility;

- Interaction;

- Course experience: Student learning;

- Course experience: Study load;

- Course experience: Inclusiveness.

Then, and according to the ABC Toolkit, the CUnit can be focused in six vertices (in a range from $0 \%$ to $100 \%)$ :

- Content acquisition;

- Collaboration;

- Discussion inquiry;

- Learning through practice;

- Producing learning artefacts.

Each CUnit is unique, so each professor can create their own type of unit and analyse it according to the tools mentioned. 


\subsection{Project Based-Learning (PBL)}

Project based-learning (PBL) consists of using practical exercises to stimulate the learning. In fact, PBL can be considered a student-centred pedagogy [29]. It involves a dynamic classroom approach where students can acquire a deeper knowledge through active exploration of real-world challenges and problems [29].

According to Stephanie Bell [30], "Project-Based Learning (PBL) is an innovative approach to learning that teaches a multitude of strategies critical for success (...) Students drive their own learning through inquiry, and work collaboratively to research and create projects that reflect their knowledge". This new method of learning is capable of bringing gleaning new, viable technology skills, so the students become proficient communicators and advanced problem solvers [30]

To help teachers understand PBL, PBLWork [31] created a comprehensive and research-based model. This publication [31] presents seven essential project design elements:

1. Challenging problem or question;

2. Sustained inquiry;

3. Authenticity;

4. Student voice and choice;

5. Reflection;

6. Critique and revision;

7. Public product. TechTeach follows these principles and also does PBL, which is essential to the success of the paradigm.

\subsection{Features}

The TechTeach paradigm encloses a set of approaches/methods grouped by two types: Classes and project.

1. Classes:
(a) Inverted with BYOD;
(b) Team-coding exercises;
(c) Quizzes about topics (to test basic knowledge);
(d) In-class activities;
(e) Learning challenges.

2. Project:
(a) Realistic and applicable exercises;
(b) Stimulate soft-skills;
(c) Cross-meetings areas, students and knowledge;
(d) Gamification system;
(e) Anonymous intra and inter evaluation.

\subsection{Methodology}

The following list presents a brief overview of the methodology.

1. Theoretical classes are inverted and should be used to do a brief explanation of the topics and to do practical exercises.

(a) Students must bring their laptop or smartphone to participate in in-class activities.

(b) Professors are encouraged to promote team-coding exercises.

i. These exercises should be executed in groups of 3 students;

ii. In each lesson, the groups must be different, and the active programmer must change. 
(c) Each class should have a different learning challenge.

(d) After classes, the students must fill a quiz (multiple-choice) to assess their knowledge on some of the addressed topics.

2. Practical classes are used to develop a realistic project and stimulate soft-skills.

(a) Each project should address a real problem of society and promote healthy competition between students.

(b) The projects should be divided into teams, and if possible, groups:

i. A team is composed by a set of groups;

ii. Each group should have different roles;

iii. The groups are responsible for implementing a set of features.

(c) Project meetings should cross different areas, students and knowledge. The sessions at classrooms should be divided:

i. By project features (groups);

ii. By project roles (teams).

(d) During the class, the professor should analyse the work done by a student and evaluate their contribution to the project using a gamification system.

(e) The projects should have three assessment points:

i. $\quad \mathrm{CP} 1$ - to verify requirements and motivate the students, in a range of three results $(10,15,20)$;

ii. $\mathrm{CP} 2$ - to assess the technical quality of the project;

iii. $\mathrm{CPF}$ - to assess the final result and the commercial potential.

(f) The project must include an anonymous peer evaluation using an $\mathrm{N}+1$ scale. Each student should have the possibility to evaluate the contribution of each teammate (including himself) for the outcome and to propose a project grade.

3. The professor is the "referee and manager" of the class ("game") and he should:

(a) Promote the team learning and the content research-Give some paths and clues to the result but not provide the final answer.

(b) Give support to students when they require it and when it is under point (a).

(c) Promote exercises that evolve learning of soft-skills (resilience, teamwork, public speaking, argumentation, work with uncertainty, others).

(d) Create a list of frequently asked questions (FAQs) with the most common issues verified by the students.

(e) Create a weekly quiz to assess the students' knowledge and implement a bonus system able to motivate the participation of students in classes.

(f) Display videos showing what is possible to do after concluding the course/subject. These videos should also explain some area trends and prognostics for the timestamps of five (5) and ten years (10). Both should show the students what they can do in the real world after concluding the course. It motivates the student to participate in the subject.

(g) Provide online presentations, videos, documents, practical examples and other essential content.

(h) Promote a continuous assessment of the subject and show that the students' opinion is relevant.

(i) Implement and define the rules of the rescue system.

(j) Create Kahoots and games able to promote interactive discussion inside the classroom.

4. Students are active learners. They are the leading "players" and should: 
(a) Study the topics before the lesson;

(b) Explore and learn new concepts;

(c) Participate in the "game", interact with the environment and practise their soft-skills;

(d) Win points to achieve the better grade possible;

(e) Contribute for the cross-learning, improvement and assessment of the CUnit.

To meet all these tasks, a set of tools can be explored.

\subsection{Tools}

TechTeach considers and advises the use of a set of tools. The following list (Table 2) presents the must-have groups of tools and the list of possible choices. It is essential to mention that the tools selected are just suggestions. Each professor can choose other solutions that better meet their needs. For example, in the case of the learning platform, this paradigm suggests the use of a tool created during the studied period (2016-2019) - ioEduc. However, professors can use other methods, such as Blackboard or Moodle. The most important information to retain from Table 2 is the types of tools that should be used for each type of platform.

Table 2. Group of tools used in TechTeach.

\begin{tabular}{cc}
\hline Type & Selected \\
\hline Game-based Learning Platform & Kahoot \\
Online Conferencing Platform & Zoom \\
Communication Platform & Slack/ioChat \\
Learning Platform & ioEduc \\
Quiz Platform & ioQuiz \\
\hline
\end{tabular}

The next subsection has a brief explanation of each selected tool. In the case of the professor using other tools, he should look for the available features and use this methodology in order to be similar.

\subsection{1. ioEduc}

ioEduc (https:/ /ioeduc.iotech.pt) is the engine behind of TechTeach. All the learning tasks are applied here. It is the hardest tool to replace because it was designed according to the methodology. However, the professor can look for similar solutions that can offer different points of collaboration. The crucial point to be noted is the capacity of it to be useful and able to motivate the students by providing some gamification resources. According to Miguel et al. [20], "ioEduc is an innovative, adaptive and user-friendly platform that can be a valuable asset in education because it provides several tools that can simplify the related parties lives. As referred earlier, ioEduc aggregates multiple modules and functionalities, in order to provide a solid working platform".

Table 3 presents the main features of ioEduc and shows what is available to the student and professor. For example, students can mark presences online and the professor can assign penalisation to them.

In this aspect, it is important to mention that ioEduc was created with the goal of supporting TechTeach Challenges and gamification tasks. The professor can use other tools like Blackboard to perform some of the required tasks. 
Table 3. ioEduc main features and user access retrieved from [20].

\begin{tabular}{lcc}
\hline Feature & Professor & Student \\
\hline Mark presence on the class & $\mathbf{X}$ & $\mathbf{X}$ \\
See presences and assign bonus & $\mathbf{X}$ & $\mathbf{X}$ \\
See class slides and other resource files & $\mathbf{X}$ & \\
Manage slides and other resource files & $\mathbf{X}$ & $\mathbf{X}$ \\
See software credentials & $\mathbf{X}$ & \\
Manage software credentials & $\mathbf{X}$ & $\mathbf{X}$ \\
Consult FAQ's & $\mathbf{X}$ & \\
Manage FAQ's and FAQ's categories & $\mathbf{X}$ & \\
Create evaluation moments & $\mathbf{X}$ & \\
Submit student's grades for each evaluation moment & $\mathbf{X}$ & \\
See student's grades at each moment & & $\mathbf{X}$ \\
See only the logged user grades & $\mathbf{X}$ & $\mathbf{X}$ \\
Create and see quizzes on ioQuiz tool and the results & & \\
Submit and see the logged user ioQuiz grades & $\mathbf{X}$ & $\mathbf{X}$ \\
Create Kahoot quizzes and see the results & & \\
Submit Kahoot quizzes & $\mathbf{X}$ & $\mathbf{X}$ \\
Create projects and teams & $\mathbf{X}$ & $\mathbf{X}$ \\
Create groups & & $\mathbf{X}$ \\
Evaluate group and each group member & $\mathbf{X}$ & \\
See the logged user's group evaluations & $\mathbf{X}$ & $\mathbf{X}$ \\
See all the group evaluations & $\mathbf{X}$ & \\
Assign penalisation to students & & $\mathbf{X}$ \\
Create calendar events to a subject & $\mathbf{X}$ & \\
See calendar events of a subject & & $\mathbf{X}$ \\
Manage Live Class & & \\
Interact with Live Class & & \\
Ask questions on the integrated chat & & \\
\hline & & \\
\hline
\end{tabular}

\subsection{2. ioQuiz}

ioQuiz is part of ioEduc and allows students to answer questions at the end of each class. The idea is to have an interactive and dynamic quiz able to assess the student's knowledge at the end of each class. Each question has points, and at the end, professors can understand what students know about each topic. This quiz should only be used to assess the critical subjects to see whether the student understands the minimum acceptable amount and the essentials of each item. At the beginning, it only allows having multiple-choice questions. This solution is being developed, and other types of questions are being added (association, screening, true or false, hidden, short answer, among others). As an alternative, professors can use, for example, Moodle to perform this task.

\subsection{3. ioChat}

ioChat is an online communication platform. It was designed as an internal communication solution and it is able to support all types of communication (text, audio and video). It can also be configured and adapted to different realities (e.g., education or business). Regarding education, the coordinating professor can, for example, create rooms for each type of class, student, professor, group or any other topic. ioChat is also integrated into ioEduc and allows omnichannel communication using a live chat. Some external features such as Zoom, Calendar, GitHub, Polls or others can also be added. The well-known Microsoft Teams can also be used as an alternative to this tool.

\subsubsection{Zoom}

Zoom (https://zoom.com) is a modern enterprise video communications cloud platform for video and audio conferencing. Its use in classrooms is increasing, and for example, one case study shows [32] how to use it to create a live-online virtual classroom. Regarding the teaching environment, Zoom has interesting features such as: Online HD streaming, hand raising, pools and breakout Rooms. 
Cloud video tools are essential to support B-learning classes. Using these types of solutions, professors can create a virtual class where, for example, each group can be split by breakout rooms.

\subsubsection{Slack}

Slack (https:/ / slack.com) is a freemium business communications tool and offers many IRC-style features, including persistent chat rooms organised by topics, private groups and direct messaging. The idea of using Slack is to complement LMS with student-centric communications. A study analysed the importance of Slack to students and how it can be used at the class [33].

\subsubsection{Kahoot}

Kahoot (https: / / kahoot.com) is a game-based learning platform that brings engagement and allows people to play at school, work or home. In the context of school, it can be used to review students' knowledge, to do formative assessments or as a break from traditional classroom activities [34]. This platform is being used in several contexts. According to a study about the effect of using Kahoot! for learning [34], the game has a positive effect on learning performance, classroom dynamics, attitudes and anxiety.

\subsection{Gamification Methods}

The use of gamification is essential to increase students engagement. In this aspect, there are many strategies and methods that can be applied. TechTeach designed a set of innovative mechanisms that can contribute to improving students' performances and increase their engagement. The following methods are an example about what can be used regarding gamification. Each professor can create his own methods.

\subsubsection{Card System}

It is an interactive system where the professor can do a continuous assessment of a student's performance. This system has two types of evaluation: Positive or negative. Regarding the negative evaluation, students can receive up to three cards:

- Yellow-First warning: The work performed is below the expected;

- Orange-Second warning: The performance is negative, and the student's future at the CUnit is critical;

- Red-The student did not make any effort to improve their participation. He did not do the minimum acceptable amount, and the level of knowledge is too low, so we can not do the work.

On the positive side, they can receive two types of cards:

- White-The student is working very well, and the professor recognises some extra effort when he is compared to the class.

- Blue-The student is a good example. The commitment level with the CUnit is high, and he deserves to be rewarded.

In both cases, the impacts of the cards should be defined by the professor. He can decide to reprove a student or decrease his grade, and alternatively, he can increase the final grade.

\subsubsection{Rescue System}

Another novelty of TechTeah is the possibility for students to rescue grades and have second chances to show their value. Each student can use this system only one time during the entire CUnit. This possibility is available to anyone who has a negative grade in some theoretic evaluation and considers that their degree is not fair. After the student asks for redemption, the professor will analyse the request, and in case of being approved, he can continue their work as usual. In this case, 
their grade is eliminated, and in the end, the final grade will represent a percentage of the achieved result. For example, imagine that the student, after the second assessment, has $12+7$ (which is bellow of the minimum grade-8): He asks for a second chance; the professor accepts it and determines that their grade will be ninety per cent $(90 \%)$ of the final result. Thus, the student, instead of reproving, will have three grades $(12+7+12)$. The second result will be removed, and the final grade will be $(12+12) / 2 \times 0.90=10.8$. This mechanism should be activated until $72 \mathrm{~h}$ after the evaluation becoming public.

\subsubsection{Online Quizes with Bonuses}

Quizzes are an excellent mechanism to assess students' knowledge about a specific topic. They are essential in the flipped classrooms. The professor can prepare a set of crucial questions about each item. Then, after the classes, the students have a limited time to answer the questionnaire and test their level of knowledge about each topic. To increase the student's motivation and participation, some bonus rules can be added. For example, the professor can promote a raffle between the classes attendants. The selected students will duplicate their results at the end of the quiz. This feature increases students' motivation to answer the quiz and allows the professor to assess the level of absorption of knowledge by the students. Since the quiz should be used to evaluate the critical subjects, the professor can, for example, repeat the explanation on some topic that had a lower level of correct answers.

\subsubsection{Interactive Surveys}

This mechanism can be used to collect students' opinions about the CUnit and professors. It can also be used to promote discussion in the classroom and ask some questions during the class. Another possibility is to create online games where the students can compete individually or in groups. It promotes the learning of soft-skills, and in addition, the professor can add some points to the game to make it more attractive.

\subsection{Other Methods}

TechTeach also wants to simplify the professor's life and work, so some other methods can be useful to motivate students and reduce the professor's workflow.

\subsubsection{Frequently Asked Questions (FAQs)}

In general, the vast majority of people recognise and know what FAQs are. FAQs is a list of the most frequently asked questions (FAQs) and their respective answers on a particular topic. It was introduced in TeachTeach due to the high number of recurring issues made by the students. For example:

- How many students did the same questions every year?

- How many questions are easy but boring to explain?

The answer is easy: Several! Then why have not the professors created their own FAQ and made it available to everyone at the beginning of CUnit? The FAQs should be grouped by topics and contain the question, the professor's answer and a link to a video or an article explaining the solution. The success of a FAQ lies in the possibility of putting the same item in diverse topics and make it searchable. This method promotes active learning and autonomy, and allows students to clarify their doubts and solve their problems without disturbing the professor.

\subsubsection{Drive}

Another vital resource is the possibility of having a cloud drive for students to research and learn more about each topic. Professors have many systems available (e.g., Google Drive, DropBox, OneDrive) that can help them share essential resources with students. In order to keep all the data 
up-to-date, the drive should be updated every year before the begin of each CUnit. They can share books, articles, white papers, videos, sounds and among other types of intuitive and digital content.

\subsubsection{Hand-Written Test}

In higher education, it is fundamental to have an individual assessment method; however, due to the number of resources available on the Internet, professors can not obligate the student to know everything. In a real life context, they can simply use "Google" to help them. Thus, the solution is easy - an individual exam should be proposed to the students; however, they are responsible for deciding what type of test they want. Three types of tests support can be proposed:

- a-without consultation;

- $\quad b$-with consultation (two pages);

- $\quad c$-with consultation (everything).

The difference between each method is difficulty. By creating a range from one to five, the scales of each proposal are:

- a-difficulty: 2 I support: 0;

- b-difficulty: 4 I support: 3;

- c-difficulty: 5 I support: 5 .

After the students make their choices, the majority wins, and the professor should prepare the test according to the decision made. In this case, the students can not contest the type of test, because they have already made their choice.

\subsubsection{Sync Mini-Tests}

This innovative way of promoting individual tests assessment arose with COVID-19. The pandemic brought on a new era of assessing students and professors need to create new ways of evaluating them online. These types of tests must be synchronised and can be one of two kinds: Theoretical or practical. Professors can use tools such as Kahoot! or HackerRank to promote this type of mini-test.

When the test is scheduled, all the students need to show up $10 \mathrm{~min}$ before the start. Then, they need to set up their environments. Typically, they should each have a screen to see the test and a device (e.g., mobile phone) to answer the questions with. The test should be done individually and quickly (no more than $30 \mathrm{~min}$ ). The professor is responsible for controlling the questions and the time.

Regarding the first type: The items should have a time range from $5 \mathrm{~s}$ up to $60 \mathrm{~s}$ and can be one of the following types: Multiple-choice, true or false, ordering, short or long. The test should also have screening questions to verify whether the student is there or not. Following the General Data Protection Regulation (GDPR), some extra features can be added, such as activating the camera or doing some interactions with the camera and student's desktop. The available answering time should be defined following the question difficulty level and considering the thinking time requested (for example, a hard question that requires more thinking should have available more time to be answered).

Regarding the second type: The professor needs to prepare a set of coding exercises, where the students need to do their work or fill white spaces. The chosen platform (e.g., HackerRanck) should be responsible for revising the code and giving a grade for each exercise. It can be used to assess small pieces of code or global and complex functions.

In both cases, each question must have a weighting according to their relevance to the CUnit. The scoring algorithm, designed by the professor, should use the results of the tool, define the weighting and keep in consideration some possible problems, such as Internet issues and the average time of answering by each student. In the end, the scoring algorithm runs and the final grade of each student is obtained. 
All the tests must run in an online and synchronised environment, where both the professor and student can be in any place. This type of test should be used to assess relevant topics of the CUnit and not to elaborate online exams.

\subsubsection{Individual Practical Assessment}

This novelty was designed to overcome students problems and limitations during the project works. Some students face some physical issues and can not work at distance. They can not be harmed, so it is crucial to give them an opportunity to show that they dominate the practical components of the CUnit. Regarding this issue, a practical project exam can be designed. The exam occurs online using a sync platform (e.g., Zoom). The professor must prepare the exam with two different type of questions:

1. Technical questions (50 $\mathrm{min}$ ), where the student needs to show that he knows how to do the exercise (e.g., technical programming, design an API, do a mock-up, other).

2. Five short questions $(10 \mathrm{~min})$ to assess the level of practical knowledge of the student.

The exam must be done under pressure and the student must share their screen with the professor. It is the last chance to get a positive grade, so a real work environment should be prepared. The professor will see the desktop and evaluate the student's work/behaviour. At the end, the professor is ready to give a grade to the student. This type of exam can overlap the oral tests and can only have the maximum grade of sixteen (16) in a range of 0 to 20 points. This limitation is due to the fact that the student cannot have the same grade as a full active student. Table 4 shows how the select tools can be used in this method.

Table 4. Learning and assessment methods.

\begin{tabular}{|c|c|c|}
\hline Method & Group & Goal \\
\hline \multirow[t]{3}{*}{ Surveys/Kahoots } & BYOD & Assess CUnit performance \\
\hline & Flipped Classes & Ask students their opinion \\
\hline & & Promote games and interactive discussions during the class \\
\hline Card System & Gamification & Alert the students about their performance \\
\hline Quiz & Flipped Classes & Assess assimilation of week concepts \\
\hline Bonus & Gamification & Motivate students to participate in classes \\
\hline Project & Skills & Assess technical and Soft-Skills \\
\hline FAQ & Flipped Classes & Help the students with the most common questions \\
\hline $\begin{array}{l}\text { Handwritten } \\
\text { test }\end{array}$ & Knowledge & Assess the expertise of doing the basis without help and syntax \\
\hline $\begin{array}{l}\text { test } \\
\text { Drive }\end{array}$ & $\begin{array}{l}\text { Skills } \\
\text { Flipped Classes }\end{array}$ & $\begin{array}{l}\text { validation } \\
\text { Help the learning process with white papers, tutorials and examples }\end{array}$ \\
\hline Rescue system & Gamification & $\begin{array}{l}\text { The possibility of rescue a grade when the student thinks that he } \\
\text { deserves more }\end{array}$ \\
\hline Game & $\begin{array}{l}\text { Gamification } \\
\text { BYOD, Skills }\end{array}$ & Play in the group, be fast, assess team knowledge and win points \\
\hline $\begin{array}{l}\text { Challenges with } \\
\text { random group }\end{array}$ & $\begin{array}{l}\text { Gamification } \\
\text { BYOD, Skills }\end{array}$ & Promote the discussion and team learning \\
\hline Final exam & $\begin{array}{l}\text { Flipped Classes } \\
\text { Gamification }\end{array}$ & The existence of the final exam is the responsibility of the students \\
\hline Sync Mini-Tests & $\begin{array}{l}\text { Knowledge } \\
\text { Gamification }\end{array}$ & $\begin{array}{l}\text { Testing the student knowledge using an online and synchronised } \\
\text { environment. }\end{array}$ \\
\hline Practical & Knowledge & Give a last chance to the student to show their practical skills \\
\hline Assessment & Skills & \\
\hline
\end{tabular}

\section{Case Study}

The methodology described in Section 3 was tested at the University of Minho during the first semester of 2019/2020 in the course unit (CUnit) of "Web Programming" (WP). This CUnit has more than one hundred (100) students and ten (10) ECTs, and occurs over 20 weeks with 15 weeks of contact. Weekly, each student has the following hours: 
- $\quad$ Theoretical (T): 2 h;

- Theoretical-practical (TP): $2 \mathrm{~h}$;

- $\quad$ Laboratory (LP): $2 \mathrm{~h}$;

- $\quad$ Non-presential: $7 \mathrm{~h}$.

\subsection{Week Plan}

In order to put TeachTeach in the field, a weekly plan was produced. Figure 3 shows the most important actions for each week. For example, the project was presented in the third week.
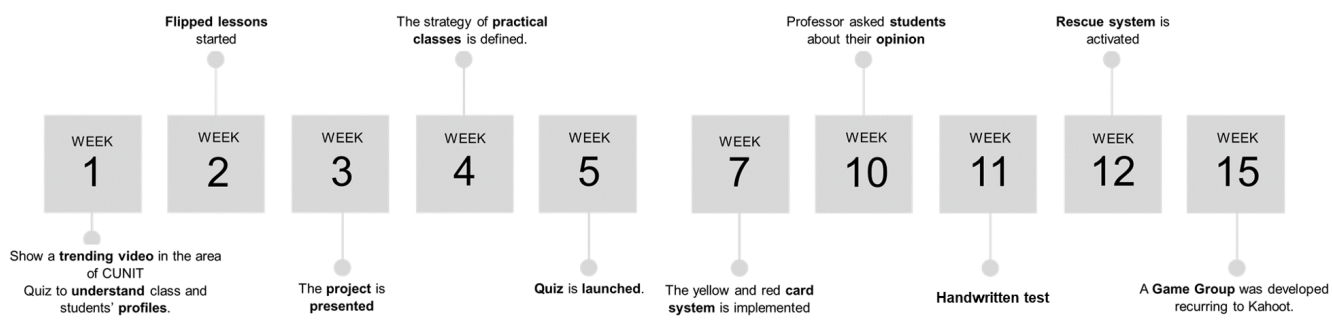

Figure 3. Week plan at Web Programming.

Then, the following list presents the most relevant tasks of CUnit plan grouped by weeks:

1st week - presentation of the CUnit and implementation of a quiz to understand the class environment and students' profiles.

1. T: A Kahoot! quiz was used to:

(a) Know the student's opinion on the type of CUnit (inverted or normal). The answer compromises the student with the process.

(b) Understand the student's expectations and their situation in the class.

2. TP: Videos about the future of Web Programming were used to motivate the students.

2nd week-flipped lessons started (in T lessons).

1. A set of exercises was proposed in each class.

2. Students were invited to seat in different places to ensure a group of three random members (in the case of online learning, the professor can create random groups in the online conferencing platform).

3. During the class, the professor goes to each group explaining some parts of the code.

4. When some critical issue was detected, the professor interrupted the exercises and explained it to everyone.

3rd week - the project was presented (in TP lessons).

1. The project was about creating a system capable of supporting the development of outdoor activities (e.g., karting, rafting, orientation).

2. A set of topics was presented, and each team chose one of them. The project was divided into three packages of features:

(a) Administration of the outdoor activity company;

(b) A mobile application for the participants;

(c) Management of the company spaces and sponsors activities.

3. A group of students developed each package. Every group had three areas: Front-end, back-end and full-stack.

4. Each team had to prepare a contract document to delivery to the professor containing the project requirements and its cost (the final grade that they desire). 
4th week-the strategy of practical classes was defined.

1. TP: All teams worked grouped by project roles (for example, all the Full-stacks worked together).

(a) The full-stacks were responsible for ensuring the correct development of the project and connecting front-end and back-end.

(b) A set of roles were defined: Product owner (team leader), group manager (one for each package) and area manager (one for each area).

(c) Students were motivated to define a weekly plan and share their experiences and difficulties during the group development.

2. LP: Each team was divided into groups in order to develop the respective features (packages).

(a) Students shared the decisions made and the tasks defined at the roles' meetings early in LP classes.

(b) The development followed the rules defined by the team during LP classes.

5 th week-the quiz was launched.

1. A quiz about the topics discussed in each $\mathrm{T}$ is available to students to answer after the class.

2. A bonus system was implemented.

(a) The quiz was available to all the students that meet the $\mathrm{T}$ class.

(b) At each class, a set of students (between 5 and 15) was randomly selected to have the bonus.

3. Each quiz was composed by a set of questions with a limit of 100 points. Selected students had their results doubled (in case of 75 points, they received 150).

7th week-the yellow and red card system was implemented.

1. LP: The participation of each student in the practical component was evaluated using a gamification card system.

(a) A student could receive up to two yellow cards. After that, they received a red card and were reproved during the practical component.

(b) This system was used as an alert system for the students. They could know whether they were not working enough, and if they received another one, they would reprove at the CUnit. Otherwise, they received the alert and improved their work.

2. The professor of laboratory classes started the analysis of the project and could surprise the students by choosing someone to show the work he did up to that moment.

3. The professor asked the students about the work done, and in case of the work done being none or too little, they admonished the student with a yellow card.

4. T: During the class, the professor showed the current probability of having a final exam. In the same lesson, he used a survey to collect the student's opinions on the CUnit performance and expectations until the moment.

10th week — the professor asked the students about their opinions (2nd round).

1. T: Several questions were asked regarding the CUnit: Methods, professors and classes.

2. This Kahoot! survey was essential to understand the student's opinion during class.

3. Students could rescue the grades achieved in the handwritten test.

11th week-handwritten test.

1. Students showed what they knew or learned.

2. This test was individual and verified the base of front-end and back-end. 
3. There was no syntax validation; only the concepts and ideas were tested. In the real-world, they can use anything to help them; however, they need to know how to start.

4. This test was used as a cut-off (binary result); i.e., some students were ready to continue and others were not.

12th week-rescue system was activated.

1. The students who were surprised by the handwritten test and thought they knew more than what the grade shown could rescue the MT (mini-test) classification.

2. The rescue system could maintain the student in the "game"; however, he needed to show more than the others. In this system, a particular focus was put in those students. Then, in case of success at the end, the final grade of MT was multiplied by $90 \%$.

15th week - a game group was developed recurring to Kahoot! (T lesson).

1. All groups competed in order to be the best team.

2. The game was composed of 20 questions about the lectured subject. In the end, the students of the three best groups received a bonus in the participation grade.

Soft-skills were trained in the context of the classes and using different variables and scenarios:

- Different coworkers;

- Solutions were presented as a puzzle;

- Work with uncertain;

- Work with different teams;

- Peer-Evaluation;

- Project and classes have challenges.

During classes, students faced some type of soft-skills challenge. For example,

- They had to work with different colleagues every week at $\mathrm{T}$ classes.

- Professors did not say the whole answer but only a part of it. Students were encouraged to work with the uncertainty and look for solutions on the Internet, slides or books;

- TP classes were distributed by team roles (back-end, front-end and full-stack).

- LP classes were organised by group and project features;

- Project work (team and individual) was evaluated by all members of the group using a peer assessment tool (available at ioEduc).

After the method being introduced, the tasks and jobs continued in the following weeks. The next section presents the weeks with assessment points.

\subsection{Assessment Points}

The control points of the project occurred during three weeks: eight (CP1), twelve (CP2) and seventeen (CPF). CP2 and CPF each had an individual and peer assessment.

Each student submitted their opinion about the grade of the group and the performance of each student. The degree of each group member varied from $n-4$ until $n+4$. The sum-up of all notes needed to be zero (0). For example, a group with a project of 12 could have students with $8(-4)$ and others with $16(+4)$. In case of a student having not done the work or worked less than twenty-five per cent $(25 \%)$, their colleagues could signalise him. The work of signalised students was then analysed by the professor and could be converted into red cards. In CP2 and CPF, the professor could attribute yellow and red cards. A direct red card could be assigned in the case of a student being incapable of proving that they worked on the project or justifying why they did not work. After $\mathrm{CP} 2$, the working plan was adjusted according to the remaining members.

Individual knowledge of each student was assessed through three mini-tests (MT) that were designed. Each one was designed to evaluate: 
1. Front-end matters (a Moodle test with a pool of questions).

2. The base of front-end and back-end (a handwritten code test without consulting and syntax validation).

3. The entirety of the content of CUnit (a Moodle test with a pool of questions).

\subsection{Practical Classes}

As mentioned before, TechTeach wants to create a real work environment with the goal of testing and training soft-skills.

The best way to do that was by creating a project able to train a set of skills, such as responsibility, leadership, uncertain, resilience and organisation. To put this in practice, a different work environment was created to mix students duties. The project had teams and groups and ran following the agile methodology of SCRUM. Figure 4 is an overview of the LP and TP classes, and for better comprehension of the figure, a caption of the scheme was added. Each group was composed of 6 people ( 2 full-stack, 2 front-end and 2 back-end). Three groups formed each LP, and these groups were part of the same team. Teams were working together at TP classes; however, the division was not by the group but by project roles. As can be seen in Figure 4, the classes were split into three different spaces, one being reserved to full-stacks, another to front-end developers and another to back-end developers. Besides that, the team, groups and areas also have a leader. Both of them had to do a weekly report and deliver it to the professor.
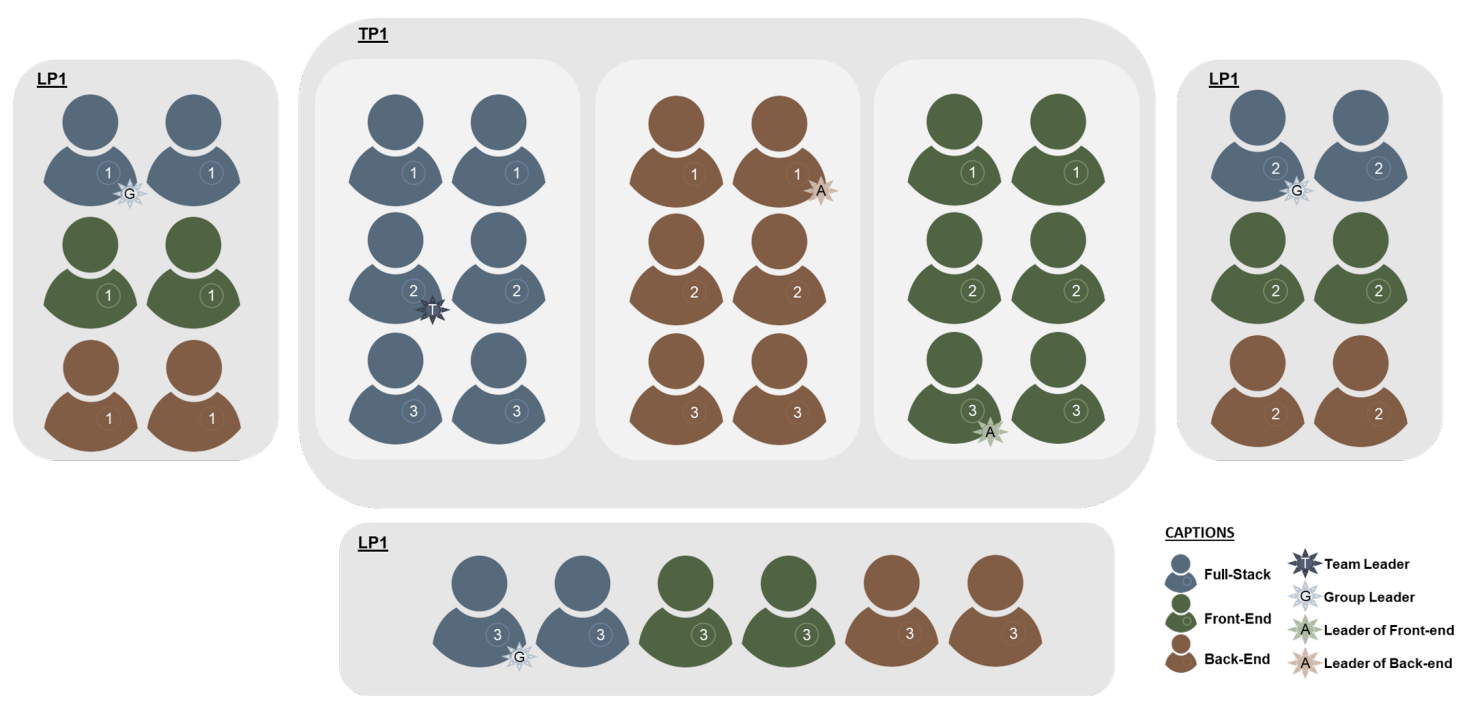

Figure 4. Pratical classes strategy.

Finally, a competitive spirit was added, and the teams also had to achieve goals and show that their solution was mostly adequate to address the issue presented. The best project received a badge.

\subsection{BYOD Platform}

ioEduc (https:/ /ioeduc.iotech.pt) [20] was used to motivate interaction and learning. ioEduc is a progressive web application (web/mobile platform) [35] designed to support teaching activities [21]. This platform was created by the author of this paper and then implemented by IOTech. ioEduc applies the concepts of bring your own device to classrooms and has a set of features:

1. Making student attendance at the classroom;

2. Taking notes of the lessons;

3. Rescue grade system;

4. Reading the slides (responsive system);

5. Assessing each teammate's work; 
6. Creating teams and groups of projects;

7. Consulting the drive and the FAQ system;

8. Accessing to a real-time and offline chat (messaging system) with the professor.

For complementing the work, interactive classes were promoted using AWS C9 (https:/ / aws. amazon.com/cloud9/)—“AWS Cloud9 is a cloud-based integrated development environment (IDE) that lets you write, run, and debug your code with just a browser" [36].

In parallel, students were instigated to explore and deploy their project using:

- GitHub (https://github.com)—a development platform inspired by the way people work. From open source to business, it is possible to host and review code, manage projects and build software alongside 40 million developers.

- Heroku (https:/ / heroku.com)—a platform as a service (PaaS) that enables developers to build, run and operate applications entirely in the cloud.

One of the most substantial aspects of this CUnit is the professor's accessibility. During the entire CUnit professors were available to help students after the classes by email. A chat is available in ioEduc to facilitate the communication between students and professor among the class.

\subsection{Gamification in Action}

Gamification is fundamental to increasing the participation and engagement of the students at a class.

\subsubsection{Card System}

The card system is composed of an ordered list of cards:

1. Yellow;

2. Orange;

3. Red.

After the 7th week, the card system was released. LP professors analysed the work performed by each student, and without warning, they addressed the students and asked what they did in the project. If the answer was satisfactory, nothing would happen. Otherwise, the student received a yellow card. It was a random process, and anyone could be interpolated. In case of it being a recurrent student, he could obtain a second yellow card. The card system was also used at the project's control points.If a student did not do anything during the project, they would receive a direct red card. If the student already had a yellow card, and the work was still not satisfactory, he would receive a second yellow card. Of the 149 students registered, there were a total of 53 penalties (35.57\%). There were 34 yellow cards (2282\%), 4 orange cards $(2.68 \%)$ and 15 red cards $(10.07 \%)$.

During this process, students who received a red card were reproved in the practical part of the CUnit. The professor can easily admonish students at ioEduc. Due to a compromise of transparency, these results were available to all students inside of the group.

\subsubsection{Rescue System}

This feature was designed after the students showed not to be prepared for a mini-test. In some cases, the professor could see that they did not understood what was expected. Some good students failed in the handwritten test, so in order to be fair, this new feature was created. In this case, thirty-five (35) students asked for redemption; thirty-four (34) passed and only one (1) was reproved.

\subsubsection{Online Quizzes with Bonuses}

After the end of each $\mathrm{T}$ lesson, students had to answer to a quiz, which was available for two days. Before ending the class, the professor used raffle (a feature available inside ioEduc) to draw a 
number of students (5 to 15). This bag of students was sorted from the list of students that attended the classroom. The attendance could be done during class at a particular moment.

\subsubsection{Individual Assessment}

This method was used to assess the knowledge level of a student. He answered a set of questions and/or did a set of basic exercises. In the end, the student had to show that they knew the main concepts and could do the basics without any type of help (e.g., Google). The idea of this approach is to define a minimum level of knowledge and perform a cut-off in the list of students. After determining the minimum level of knowledge, all the students were evaluated following a "checklist". Thus, if the background was considered enough, they would achieve the grade one (1) - "you can continue your path at the CUnit". Otherwise, they would receive the rate zero (0) "the level of knowledge isn't enough, you are reproved". All the methods can be fallible, so the students could rescue their grade using the rescue system.

\subsubsection{Exam}

An algorithm was created to find the possibility of the students having an exam (percentage from 0 to 100) at the end of the semester. This algorithm used a Likert Scale [37] from 1 to 5 and took into six aspects:

1. The motivation of the students (positive);

2. Preparation to the classroom (positive);

3. Noise during the lesson (negative);

4. Fatigue of the professor at the end of class (negative);

5. Meeting class Goals (positive);

6. Hoarseness (negative).

This algorithm was calculated at the end of each $\mathrm{T}$ class. Then, the students could know the probability of having an exam in three weeks: 6,10 and 14 . After the fourteenth week, students saw the final decision. In case of the percentage being higher than fifty per cent $(50 \%)$, the exam would occur; otherwise, there was no exam. In this case, the percentage was forty-six per cent $(46 \%)$ so the exam did not occur.

\subsubsection{Interactive Surveys}

An interactive group game was performed in the last class, using Kahoot!. This game was composed of 20 time-limited multi-choice questions about the CUnit topics. Each group had a leader which had the mobile phone (where they must answer) and was at the centre of the team. Thus, all members of the group could participate in the discussion, but only one of the elements (team leader) was responsible for choosing the group choice answer. The time was essential-the quicker the students were, the more points they could win. In the end, all the students of the best five groups received extra points in the final grade of CUnit $(1,0.75,0.5,0.3$ and 0.2 respectively). Most recently, this type of approach was used to do mini-tests.

\subsubsection{Individual Assessment Methods}

Recently, this group of methods was defined and put in practice in another CUnit. Both methods presented in Section 3.7.4 were applied.

Students participated in an online sync quiz using Kahoot! and Zoom with 30 questions. These'questions were about the main topics of the CUnit and had three screening questions (math, number of the students and opinion). In the end, students had to answer two additional questions: "Was the test easy?" and "Do you approve this type of test?" These two questions were essential to assess method engagement. 
Regarding the practical component, an exam of integration was prepared. The student had fifty (50) minutes to show that they knew how to create an API and integrate it with an enterprise resource planning system (ERP). Some questions were defined to see whether they knew how to make items and clients. In the last ten (10) minutes, five (5) quick and direct questions were answered by the students. This practical test was realised online using Zoom and a shared screen.

Most recently, an extra model was defined and applied-a sixty (60) minutes exam with thirty (30) minutes for the theoretical part (Kahoot! mini-test), and thirty (30) minutes for a practical component (development of a simple RESTful API and five questions) was designed. This type of exam can be used to assess whether the student had a minimum level of knowledge to obtain a positive grade. It could only be used in additional opportunities (e.g., special exam).

\subsection{Quality Assessment of the UC}

All the students were invited to evaluate the CUnit and participate in the definition of CUnit during the classes. They were asked to participate in interactive surveys (Kahoot!) by answering questions about the performances of professors, type of classes, motivation, expectations, etc.

The assessment surveys were performed following this plan:

- Q1-At the beginning of the class-first week;

- Q2-At the middle (one or two times) of the semester-week 7;

- $\quad$ Q3-At the end-last week.

The first questionnaire (Q1) was used to understand the learning environment and student's expectations/behaviour. The Q2 was used to make changes in real time, while the classes were happening. The student had the opportunity to assess the CUnit and the professor could act in accordance with the answers. The last questionnaire (Q3) was essential to understand the quality of the CUnit, the importance of the topics addressed and the performance of the professors. Q3 was also critical to prepare the classes for the next year: The received feedback could be used as an input for the following year. All the responses could be or not anonymous. Regarding this case study, the CUnit is continuously changing and improving. Every year, the student's answers and opinions are used to make this CUnit more attractive and increase the student's engagement.

Table 5 presents the evaluation levels of the questionnaires. For each question, there were 2 to 4 options available. For example, regarding the question 1.4 (Q1.4), the available options were: "I would still not go" (option 1); "I would see" (option 2); "In that case, I would go" (option 3); "I go regardless of the class" (option 4). Table 5 represents all the questions and all the answer options available.

Table 5 has two type of scales-numeric and alpha. The numeric scale represents levels of opinions that can be represented by

1. Negative I Weak;

2. Neutral I Acceptable;

3. Good I Interesting;

4. Positive I Excellent.

The alpha scale is used to categorise the professors according to the students' experience:

A. Dominates the subject but does not know how to teach;

B. Dominates the subject and knows how to teach;

C. Does not dominate the subject and does not know how to teach;

D. It is enough to "get by". 
Table 5. Assessment classes questions.

\begin{tabular}{|c|c|c|c|c|c|}
\hline ID & Question & 1 & 2 & 3 & 4 \\
\hline Q1.1 & Typology of theoretical classes & Traditional & Interactive & - & - \\
\hline Q1.2 & Participation & I am obligated & I do not attend & I want to learn & - \\
\hline Q1.3 & Web programming & Boring & The future & Middle ground & - \\
\hline Q1.4 & If the classes were interactive... & $\begin{array}{l}\text { I would still not } \\
\text { go }\end{array}$ & I would see & $\begin{array}{l}\text { In that case, I } \\
\text { would go }\end{array}$ & $\begin{array}{l}\text { I go regardless } \\
\text { the class }\end{array}$ \\
\hline Q1.5 & I am here because... & I am obligated & $\begin{array}{l}\text { I want to learn } \\
\text { WP }\end{array}$ & $\begin{array}{l}\text { I need it to finish } \\
\text { my degree }\end{array}$ & $\begin{array}{l}\text { I'm in "tourist } \\
\text { mode" }\end{array}$ \\
\hline Q1.6 & WP importance for your future & None & Little & Some & Big \\
\hline Q2.1 & Global appreciation of the CUnit & Ver positive & Positive & Negative & No opinion yet \\
\hline Q2.2 & Global appreciation of T classes & Interesting & Boring & Tiring & Normal \\
\hline Q2.3 & Global appreciation of TP classes & Interesting & Boring & Can be different & Normal \\
\hline Q2.4 & Global appreciation of $\mathrm{P}$ classes & $\begin{array}{l}\text { I like the classes } \\
\text { in group }\end{array}$ & $\begin{array}{l}\text { I prefer working } \\
\text { alone }\end{array}$ & No opinion & Weak \\
\hline Q2.5 & What have you learned yet? & Nothing yet & Learned much & The same & - \\
\hline Q2.6 & At this moment you are... & Motivated & Unmotivated & I feel the same & - \\
\hline Q3.1 & $\begin{array}{l}\text { Clarity in the presentation of } \\
\text { contents }\end{array}$ & 1 & 2 & 3 & 4 \\
\hline Q3.2 & Capacity of motivating students & 1 & 2 & 3 & 4 \\
\hline Q3.3 & $\begin{array}{l}\text { Strategies/methodologies } \\
\text { adequacy }\end{array}$ & 1 & 2 & 3 & 4 \\
\hline Q3.4 & Work environment created & 1 & 2 & 3 & 4 \\
\hline Q3.5 & Contents importance/relevance & 1 & 2 & 3 & 4 \\
\hline Q3.6 & Global T class appreciation & 1 & 2 & 3 & 4 \\
\hline Q3.7 & Global CUnit-TP appreciation & 1 & 2 & 3 & 4 \\
\hline Q3.8 & Global CUnit-LP appreciation & 1 & 2 & 3 & 4 \\
\hline Q3.9 & $\mathrm{T}$ and TP Professor appreciation & $\mathrm{A}$ & B & C & $\mathrm{D}$ \\
\hline Q3.10 & LP Professor appreciation & A & B & C & $\mathrm{D}$ \\
\hline Q3.11 & $\begin{array}{l}\text { Professor's } \quad \text { performance } \\
\text { appreciation-(class and name) }\end{array}$ & 1 & 2 & 3 & 4 \\
\hline Q3.12 & $\begin{array}{l}\text { Professor's } \quad \text { performance } \\
\text { appreciation-(class and name) }\end{array}$ & 1 & 2 & 3 & 4 \\
\hline Q3.13 & Should ioEduc be a bet? & No & Maybe & Yes & Definitely \\
\hline Q3.14 & $\begin{array}{l}\text { Do you approve the use of BYOD } \\
\text { concept of the CUnit? }\end{array}$ & Yes & No & - & - \\
\hline Q3.15 & Motivation to work in the area & None & Little & Some & Big \\
\hline Q3.16 & Global UC appreciation & 1 & 2 & 3 & 4 \\
\hline
\end{tabular}

\section{Discussion and Results}

TechTeach represents innovation in the way professors and students work at the classroom. The introduction of TechTeach in the Web Programming class at the University of Minho was a challenge, but ended up being a success. This was only possible due to the "open mindset" of the professors and students of this CUnit. To a better comprehension of the CUnit plan, Table 6 presents the description and goals of each type of class (T, TP, LP). For example, at the TP classes, students were grouped by team and in accordance with their roles (in accordance to Figure 4). The main goal was to promote the discussion, team learning and cross-learning.

The CUnit is assessed recurrently regarding three aspects: Participation, theoretical and practical. Participation is assessed by the results achieved with the quizzes. The mini-tests evaluate the theory, and the practice is measured throughout the project. Each method has a percentage associated. Participation has a particularity that is essential to mention: The best grade without bonus has the maximum degree. For example, if the higher number of points without bonus is eight-hundred and fifty (850), this student will have twenty (20). All quizzes (with a bonus) having a result higher than eight-hundred and fifty (850) also have twenty points (20), and all the other students have their grades in percentages of eight-hundred and fifty (850). In this phase, it is essential to dominate the methods used to make this subject more attractive and interactive. 
In Table 7, it is possible to consult the methods used and the goal of each one. For example, yellow card system was used to alert the student about his performance in the project. FAQs and drive were used to complement the teaching and give some tips and tutorials to students.

Table 6. Description and goal of each class.

\begin{tabular}{|c|c|c|}
\hline Type of Class & Description & Goal \\
\hline $\mathrm{T}$ & $\begin{array}{l}\text { Theoretical classes in groups of three } \\
\text { students (random). } \\
\text { Flipped classes. } \\
\text { Discussion and analysis of the week topics. } \\
\text { Exercising and practising examples. }\end{array}$ & $\begin{array}{l}\text { Practice the concepts learned at home before } \\
\text { class. } \\
\text { Encourage group discussion and difficulty } \\
\text { analysis; } \\
\text { Share knowledge and experiences with } \\
\text { different teammates. }\end{array}$ \\
\hline $\mathrm{TP}$ & $\begin{array}{l}\text { Students are grouped by team and area/role. } \\
\text { The tasks of the project are defined. }\end{array}$ & $\begin{array}{l}\text { Team working, test Soft-Skills, } \\
\text { Promote the discussion, team learning and } \\
\text { cross-learning }\end{array}$ \\
\hline LP & $\begin{array}{l}\text { Develop, in group, the tasks defined by the } \\
\text { team. } \\
\text { Monitoring of the project; } \\
\text { Individual evaluation of the work (IEW). } \\
\text { Support and monitoring the development of } \\
\text { group projects, including feedback on their } \\
\text { status; }\end{array}$ & $\begin{array}{l}\text { Control Point-Monitoring and Evaluation } \\
\text { of Project Status } \\
\text { Motivate team work. } \\
\text { Identify the students who are and are not } \\
\text { working according to the rules. }\end{array}$ \\
\hline Non-Presential & $\begin{array}{l}\text { Reading, studying and analysing of slides } \\
\text { and CUnit book. } \\
\text { Systematisation of the concepts, principles } \\
\text { and methods presented. } \\
\text { Preparation for the next lectures. } \\
\text { Development of a group project. } \\
\text { Participate in the quizzes of topics. }\end{array}$ & $\begin{array}{l}\text { Explore the capability of self-learning and } \\
\text { studying something new. } \\
\text { Assess the students' knowledge. }\end{array}$ \\
\hline
\end{tabular}

Regarding the evaluation of the CUnit quality, three quizzes were performed. The professor asked students the questions presented in the Table 5. The results of the first week are presented in Table 8 . The vast majority of students preferred interactive classes (Q1.1-94.92\%), and at the beginning of the classes, most students (Q1.2) were motivated and wanted to learn (83.61\%). In the same question, some of them confessed that they feel "obligated" to be there (13.11\%), and others $(20.97 \%)$ to be in "tourist mode". It is important to mention that this questionnaire was only answered by students that appeared in the first class (63 students).

Table 9 highlights the most relevant topics regarding the assessment methods. The survey Q2 was answered by seventy-three students (73), and Q3 was answered by ninety-three students (93). The possible answers range from the options provided in the Table 5.

Regarding Q2, it is important to mention that more than eighty-nine per cent $(89.85 \%)$ of students assumed they had learned a lot until the middle of the semester, and most of them considered the classes "interesting" (51.39\% and $43.24 \%$ ) or "normal" (36.11\% and $36.49 \%)$.

The success of this method and the capacity of it to motivate the students can be proved by some of the answers provided. As can be observed in Table 9, most of the answers were positive (the responses gave 3 or 4 points): More than eighty-seven per cent $(87.89 \%)$ to Q3.2 ("What is the capacity of the professor to motivate students") and more than eighty-two per cent (82.27\%) to the question Q3.3 ("Are the strategies/methodologies adequate?"). The last results that are important to mention are the answers achieved by question 3.4 ("How is the work environment created")—no one disliked it, and more than ninety-two per cent (92.68\%) considered it as "good" or "excellent". 
Table 7. Learning and assessment methods.

\begin{tabular}{|c|c|c|}
\hline Method & Group & Goal \\
\hline \multirow[t]{3}{*}{ Surveys/Kahoots } & BYOD & Assess CUnit performance \\
\hline & Flipped Classes & Ask students about their opinion \\
\hline & & $\begin{array}{l}\text { Promote games and interactive discussions during } \\
\text { the class }\end{array}$ \\
\hline Card System & Gamification & Alert the students about their performance \\
\hline Quiz & Flipped Classes & Assess assimilation of week concepts \\
\hline Bonus & Gamification & Motivate students to participate in classes. \\
\hline Project & Skills & Assess technical and Soft-Skills \\
\hline FAQ & Flipped Classes & $\begin{array}{l}\text { Help the students with the most common } \\
\text { questions }\end{array}$ \\
\hline Handwritten test & $\begin{array}{l}\text { Knowledge } \\
\text { Skills }\end{array}$ & $\begin{array}{l}\text { Assess the expertise of doing the basis without } \\
\text { help and syntax validation }\end{array}$ \\
\hline Drive & Flipped Classes & $\begin{array}{l}\text { Help the learning process with white papers, } \\
\text { tutorials and examples }\end{array}$ \\
\hline Rescue system & Gamification & $\begin{array}{l}\text { The possibility of rescue a grade when the student } \\
\text { think that he deserves more. }\end{array}$ \\
\hline Game & $\begin{array}{l}\text { Gamification } \\
\text { BYOD, Skills }\end{array}$ & $\begin{array}{l}\text { Play in the group, be fast, assess team knowledge } \\
\text { and win points }\end{array}$ \\
\hline Challenges with random groups & $\begin{array}{l}\text { Flipped Classes } \\
\text { BYOD, Skills }\end{array}$ & Promote the discussion and team learning \\
\hline Final exam & $\begin{array}{l}\text { Flipped Classes } \\
\text { Gamification }\end{array}$ & $\begin{array}{l}\text { The existence of the final exam is the responsibility } \\
\text { of the students. }\end{array}$ \\
\hline
\end{tabular}

Table 8. Answers of the survey preformed at the first class.

\begin{tabular}{lrrrr}
\hline Question ID & $\mathbf{1}$ & $\mathbf{2}$ & $\mathbf{3}$ & $\mathbf{4}$ \\
\hline Q1.1 & $5.08 \%$ & $94.92 \%$ & $0.00 \%$ & - \\
Q1.2 & $13.11 \%$ & $3.28 \%$ & $83.61 \%$ & - \\
Q1.3 & $3.17 \%$ & $65.08 \%$ & $31.75 \%$ & - \\
Q1.4 & $1.58 \%$ & $38.10 \%$ & $22.22 \%$ & $38.10 \%$ \\
Q1.5 & $1.61 \%$ & $37.10 \%$ & $40.32 \%$ & $20.97 \%$ \\
Q1.6 & $0.00 \%$ & $1.64 \%$ & $45.90 \%$ & $52.46 \%$ \\
\hline
\end{tabular}

Table 9. Answers of the survey preformed during the CUnit (week 7-Q2 and week 15-Q3).

\begin{tabular}{rrrrr}
\hline Question ID & $\mathbf{1}$ & $\mathbf{2}$ & $\mathbf{3}$ & $\mathbf{4}$ \\
\hline Q2.1 & $55.23 \%$ & $25.37 \%$ & $1.49 \%$ & $17.91 \%$ \\
Q2.2 & $51.39 \%$ & $2.78 \%$ & $9.72 \%$ & $36.11 \%$ \\
Q2.3 & $43.24 \%$ & $5.41 \%$ & $14.86 \%$ & $36.49 \%$ \\
Q2.5 & $1.45 \%$ & $89.85 \%$ & $8.70 \%$ & $0.00 \%$ \\
Q2.6 & $56.16 \%$ & $15.07 \%$ & $28.77 \%$ & $0.00 \%$ \\
Q3.2 & $1.23 \%$ & $9.88 \%$ & $43.21 \%$ & $45.68 \%$ \\
Q3.3 & $2.53 \%$ & $15.19 \%$ & $50.63 \%$ & $31.65 \%$ \\
Q3.4 & $0.00 \%$ & $7.32 \%$ & $53.66 \%$ & $39.02 \%$ \\
Q3.5 & $1.28 \%$ & $3.85 \%$ & $30.77 \%$ & $64.10 \%$ \\
Q3.6 & $1.25 \%$ & $13.75 \%$ & $55.00 \%$ & $30.00 \%$ \\
Q3.13 & $0.00 \%$ & $39.72 \%$ & $30.14 \%$ & $30.14 \%$ \\
Q3.14 & $95.65 \%$ & $4.35 \%$ & - & - \\
\hline
\end{tabular}

In the end, an anonymous questionnaire was disseminated with the students to get their feedback (open answers) about the following topics:

1. CUnit-positive aspects;

2. CUnit-aspects to improve; 
3. ioEduc-your opinion on the platform (positive aspects/negative aspects/aspects to consider);

4. Comments/suggestions/global observations.

In order to increase the participation of the students, this questionnaire was part of the last mini-test. In the case study, the total number of answers was one hundred and fifty four (154), so ninety-nine per cent (99\%) of the students participated in the mini-test.

Figures 5-7 exhibit the bag of words of each question (1, 2 and 4). The analysis of ioEduc (question 3) was performed in the respective paper [20]. Figure 5 shows the list of the most used words by students when mentioning positive aspects.

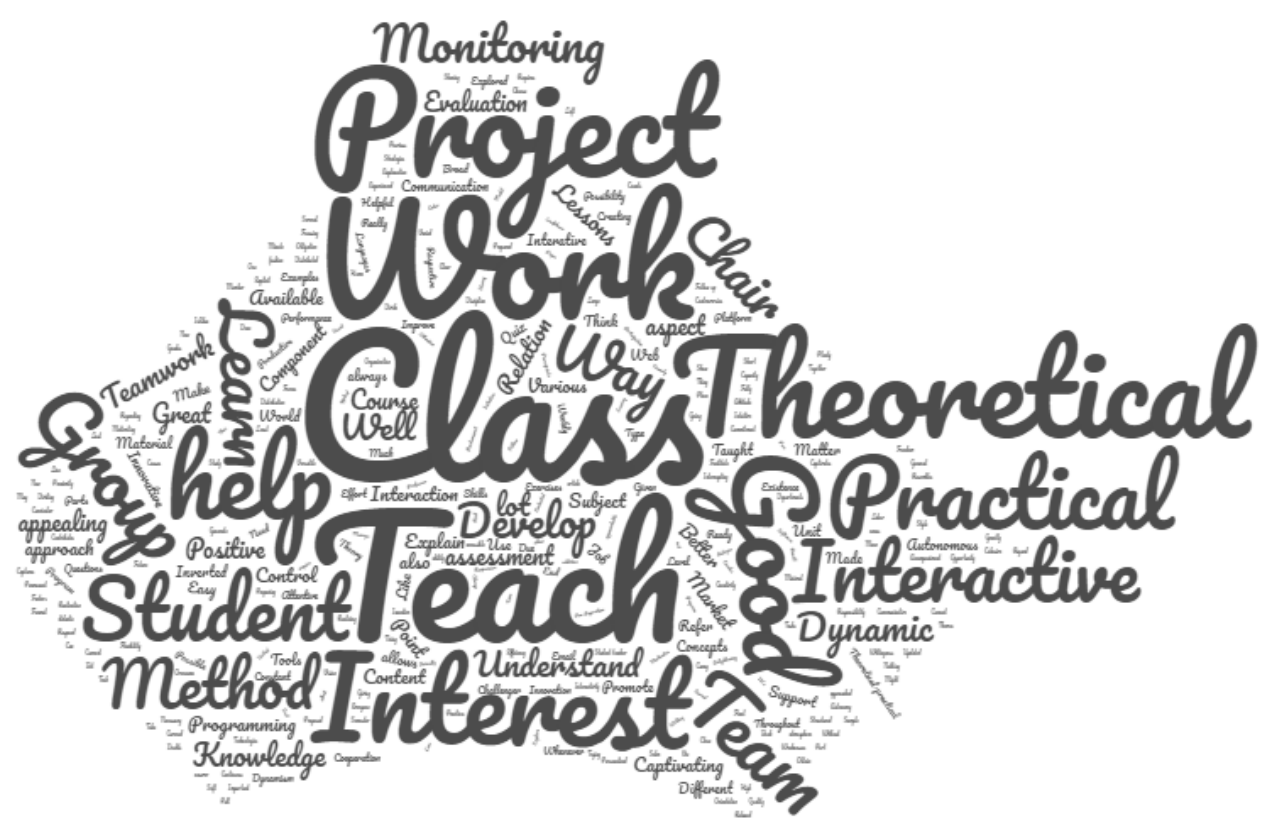

Figure 5. Positive aspects of the CUnit.

As an example of interpreting the figures, in Figure 5, the most mentioned word was "classes". Students considered the interactive character and it being a novelty as positive aspects. The next list presents the most mentioned aspects:

- Interesting, interactive, dynamic and captivating classes;

- Development of soft-skills (e.g., teamwork, creativity, flexibility, confidence);

- Accompaniment during classes and monitoring of the project by the teaching team;

- Assessment methods;

- The project and the CUnit being very practical.

Even though question 2 addressed less positive aspects, students used positive words (e.g., "good", "interesting" and "well") to show what could be different. Thus, students identified the following aspects as the ones that needed improvement:

- Communication/coordination between the professors;

- The difficulty level and high demand of the work;

- The number of students in the classroom/CUnit/project teams;

- Some components/issues of the assessment methods;

- Different levels of knowledge by the students.

Figure 6 shows the most used words associated with the question regarding the aspects that need to be improved. 


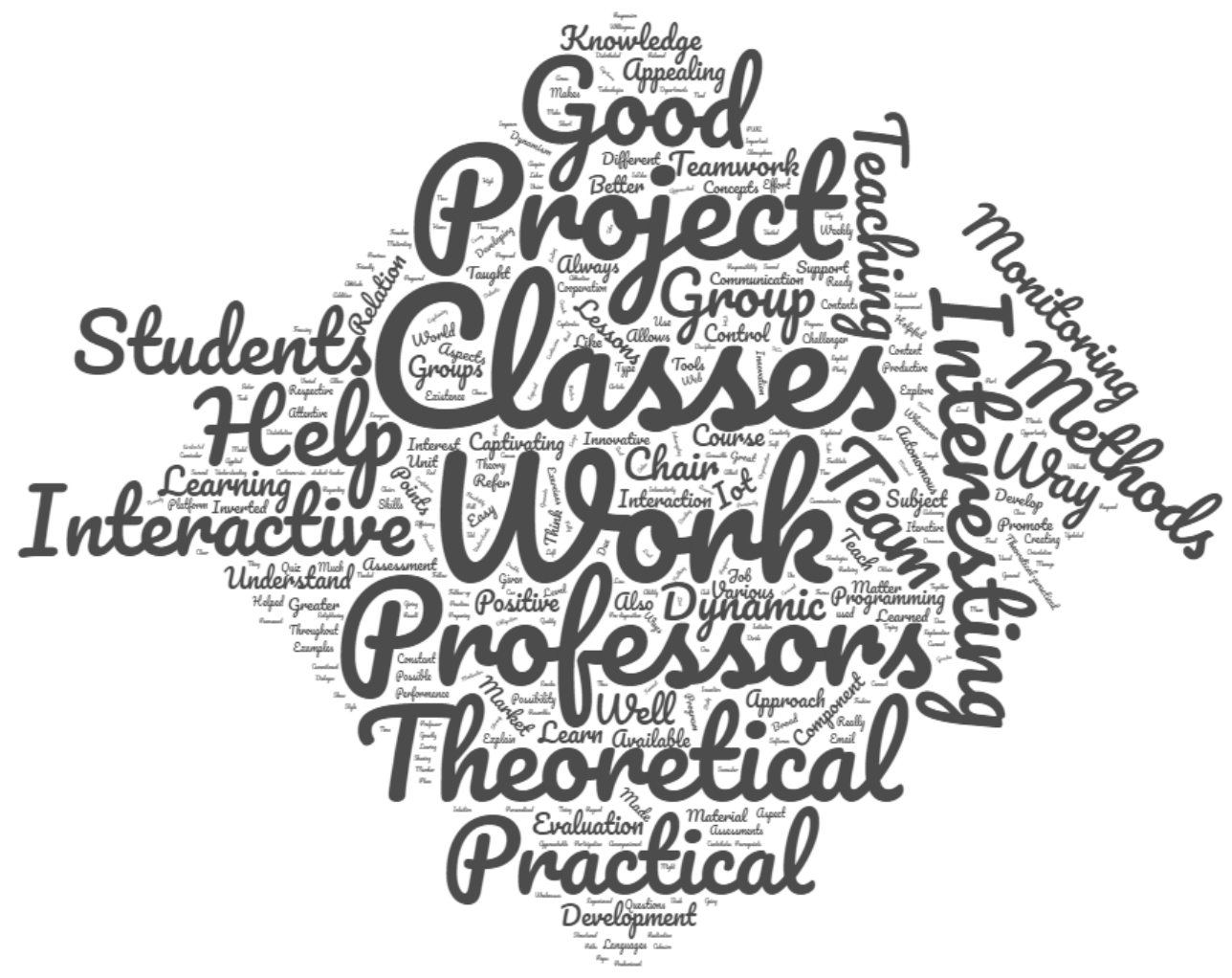

Figure 6. Improvements needed at the CUnit.

In the last question (Q4), students were encouraged to share their opinions and give suggestions about the CUnit. Generally, the students were delighted with the CUnit (e.g., "really enjoyed", "best subject so far"; "thank you"; "overall, I think WP was one of the CUnit[s] that I most enjoyed having"); however, some of them gave some other suggestions:

- Smaller groups.

- More follow-up with practical examples.

- Improve practical classes.

- Explore more the competitive components between teams. Due to this competition, more cohesive projects could arise.

- More opportunities for redemption.

Regarding the part of giving their opinion and/or suggestions, the next Figure 7 shows the must used words.

Finally, the sync mini-test and individual practical project are two recent "add-ons". Thus, they were tested in two distinct CUnits- "Web Programming II" and "Implementation of Integrated Systems". Then, and to address the viability of sync mini-test, two questions were added at the end:
A. "Was the test easy?"
B. "Do you approve this test model?"

with the following range of options:

1. Very Easy I No;

2. Easy I Maybe;

3. Hard I Yes, it was interesting;

4. Very Hard I Yes, definitely; 
5. No answer.

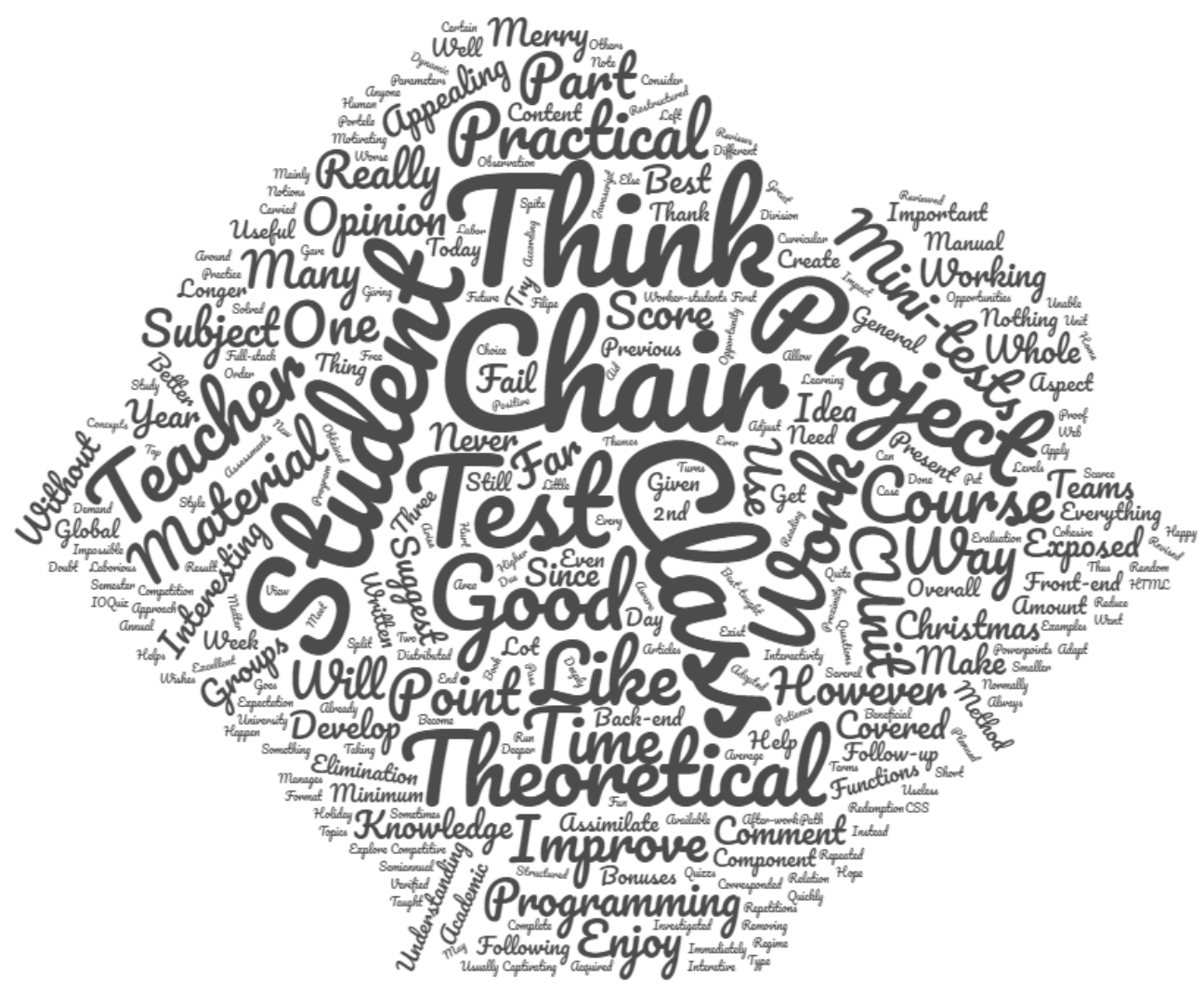

Figure 7. Students' suggestions/opinions.

For example, level 3 of question A ("Was the test easy?") was "hard". This choice represents thirty-four per cent $(34.48 \%)$ of the answers. Both questions were answered by twenty-nine students (29). In Table 10, it is possible to observe that most of the students considered the test easy $(55.17 \%)$ and almost sixty-nine per cent $(68.96 \%)$ of the students approved this assessing method.

Table 10. Assessment of the sync mini-test.

\begin{tabular}{lrrrrr}
\hline & $\mathbf{1}$ & $\mathbf{2}$ & $\mathbf{3}$ & $\mathbf{4}$ & $\mathbf{5}$ \\
\hline Was the test easy? & $3.45 \%$ & $55.17 \%$ & $34.48 \%$ & $3.45 \%$ & $3.45 \%$ \\
Do you approve this test model? & $20.69 \%$ & $37.93 \%$ & $31.03 \%$ & $6.90 \%$ & $3.45 \%$ \\
\hline
\end{tabular}

In terms of the individual practical project, it was requested by three students. Two of them $(66.66 \%)$ were approved. They considered the test adequate to the goal of showing whether they knew or not the minimum practical requirements. On the other hand, the other student did not achieve a positive grade. He quit the practical exam $10 \mathrm{~min}$ after starting it. He recognised that he was not prepared and did not master the basics concepts. The results show that it is a good and sensible way to give a last (special) opportunity to the students to achieve a positive grade.

To understand the case study and to have a better comprehension of how it can be performed, a set of essential tasks were defined, and Table 11 represents a map with the possible tools. By analysing Table 11, it is possible to observe that the main CUnit tasks (e.g., launching marks, registering attendance, evaluating teams and groups) can be performed-for example, by using a learning platform (e.g., Moodle or Blackboard). 
Table 11. Tasks vs. platform.

\begin{tabular}{ll}
\hline Task & Type of Platform \\
\hline Launch marks/results & Learning Platform \\
Regist attendence & Learning Platform \\
Create and choose schedules/classes & Learning Platform \\
Create teams and groups & Learning Platform \\
Evaluate teams and groups & Learning Platform \\
Create and perform mini-tests & Game-based Learning Platform \\
Teach the class & Online Conferencing Platform \\
Share complementary material & Learning Platform \\
Create conversation rooms & Online Conferencing/Communication Platform \\
Clarify student's doubts & Online Conferencing/Communication Platform \\
Schedule meetings & Scheduling Platform \\
Interact with students during class & Online Conferencing/Communication Platform \\
Make quizzes & Game-based Learning Platform \\
Send messages to the groups & Communication Platform \\
Prepare interactive classes (e.g., intelligent boards) & Learning Platform \\
\hline
\end{tabular}

To assist with the comprehension and analysis of Table 11, the following list offers a better understanding of how well-known tools can be used by professors who want to explore TeachTeach:

- Learning platform: Moodle, Blackboard, Google Classrooms or AWS for education;

- Game-based learning platform: Kahoot, Voxvote, Slido or Quizizz;

- Online conferencing platform: Zoom, Blackboard Collaborate, MS Teams, Google Meet or Jitsi;

- Communication platform: Slack, MS Teams, Rocket Chat or Discord;

- Scheduling platform: Calendly, Doodle, Outlook or Google Calendar.

\section{Conclusions and Future Work}

Reflecting on the transformations associated with the Bologna Process, worldwide proponents, and various opinions emerged [2]. It changed the way of teaching, and new strategies were defined. Besides that, the world is growing fast, and professors need to be ready for those changes. It is essential to invest in new ways of motivating students and promote the training of soft-skills. Thus, to conclude this work, it is fundamental to answer the main question and explain: "why is it interactive and innovative?" TechTeach approach motivates the use of new technologies and methods to motivate students and promote continuous and active learning.

This paper showed new approaches that can be explored in computer science classrooms. The presented approach wants to motivate professors to explore different strategies to create active learners instead of following a traditional method. The most relevant aspects are:

1. Gamification used to drive participation, evaluate a student's involvement in the classes and their intervention in the project;

2. Project and flipped classes used to improve skills;

3. BYOD was put in practice using a PWA named ioEduc;

4. Continuous assessment of the CUnit performed by the students;

5. Rescue system available to students to contest the grade;

6. Hand-written test used as a cut-off system to verify whether the student has the minimum knowledge required.

To do a proof of concept of the approach as recommended, a case study was developed at the CUnit of Web Programming. This method was fully tested in one CUnit and partially tested in other two CUnits. The complete test was done in a CUnit that has 10 ECTS and is part of the information system course from University of Minho. Regarding the case study presented in this article, a set of soft-skills was successfully trained: 
- Problem solving;

- Decision-making;

- Responsibility;

- Cross-learning;

- Positive attitude;

- Resilience;

- Team Working;

- Communication;

- Negotiation;
- Reflection and clarification;

- Influencing;

- Commitment;

- Dealing with aggression;

- Stress management;

- Listening skills;

- Counselling skills;

- Presenting.

It is possible to ensure a correct elaboration of a B-learning CUnit with/without virtual classes (until $100 \%$ of online appearances), being supported by online resources. The results demonstrate the students' interest and predisposition to this type of class. Thus, this approach revealed itself to be a success. The percentage of attendance at classes was around eighty-five $(85 \%)$, and eighty-seven per cent $(87 \%)$ of the answers provided in the last quiz classified the engagement approach as "good" or "excellent". Eighty-one per cent $(81 \%)$ considered the methods and strategies used as "good" or "excellent".

The scientific community should look up to Tables 7 and 11 as some examples of what can be done and take some ideas to their classes. Table 5 can be used as a possible example of how they can assess the quality of their CUnit.

In terms of digital lessons and online learning, this method will also be improved to consider non-presential classes. Even though this new situation provoked by COVID19 brings new challenges, TechTeach can be easily adapted to different types of lessons (synchronous or asynchronous). For example, ioEduc can be used to share slides online and other online meeting tools (e.g., Zoom, Collaborate, Teams, among others) can also be used to follow the work group. Kahoot! and ioEduc can also be used to provide the assessment tests.

Regarding the year 2020/2021, the classes of the CUnit (used as the case study) will run in B-learning, where one hundred per cent $(100 \%)$ of the classes are online. This model was chosen in order to keep the teaching quality and make all the learning environment safe. For example, ioChat was designed to have a virtual conversation room for each group, team, class, professor, student and other. They are grouped and organised inside the platform. Each room has text, audio and video facilities, where the students can work, and the professor can participate. It will be a new experience in this challenging reality, and some feedback will soon be provided. The chosen tools are:

- Learning platform-ioEduc and C9;

- Game-based learning platform—ioQuiz and Kahoot;

- Online conferencing platform-ioChat and Zoom;

- Communication platform-ioChat;

- Scheduling platform-Calendly.

Another significant contribution to this approach is the fact that the student's performance/work generates a lot of useful data to categorise the type of students and understand the best path to success. With that, it will be possible to improve the CUnit quality and the student's performance. Regarding this issue, it is essential to mention that students have to accept General Data Protection Regulation (GDPR) rules, and that all the critical data is protected. Thus, the collected data to statistical analysis can be exported without the student identification. This analysis will be the target of the next study/publication.

Concluding, and as can be observed on the case study (one full and two partial), students like and approve TechTeach paradigm. The achieved results gave some confidence to continue this mission of turning the Computer Science/Information Systems CUNits more attractive and engagement. 
In the future, a benchmarking and SWOT analysis will be performed in order to make a deeper comparison between TechTeach and other similar solutions. Although this paradigm addresses several methods, it is essential to understand how different is it from the other (more focused) solutions.

Finally, TechTeach is in continuous improvement, and some new methods/features/mechanisms can be added. The expectation is also to test this paradigm with different CUnits and professors. The future upgrades will be tuned by the students and validated by all the professors team. In the future, besides these improvements, some data science studies will be performed to identify possible patterns and/or to predict students behavioural at the classroom/CUnit.

Funding: This research received no external funding.

Acknowledgments: I want to thank IOTECH for supporting the project and Rita Miranda for their support in the review process.

Conflicts of Interest: The authors declare no conflict of interest.

\section{References}

1. Ramírez-Montoya, M. Inverted learning environments with technology, innovation and flexibility: Student experiences and meanings. J. Inf. Technol. Res. 2016, 9, 18-33. [CrossRef]

2. Araújo, C.; Silva, V.N.; Durães, S.J. The Bologna Process and curricular changes at higher education: What are skills for? Educação e Pesquisa 2018, 44, e174148.

3. Doyle, P. Gamification and student motivation. Interact. Learn. Environ. 2016, 24, 1162-1175.

4. Parra-González, M.E.; López Belmonte, J.; Segura-Robles, A.; Fuentes Cabrera, A. Active and Emerging Methodologies for Ubiquitous Education: Potentials of Flipped Learning and Gamification. Sustainability 2020, 12, 602. [CrossRef]

5. Álvarez, W.F.G.; Santamaría, H.S.; García, M.R. Flipped classroom and problem-based-learning in higher education. In Proceedings of the 2017 International Conference on Information Systems and Computer Science (INCISCOS), Quito, Ecuador, 23-25 November 2017; pp. 260-267.

6. Klyoster, A.M.; Elkin, V.V.; Melnikova, E.N. Project-Based Learning in the System of Higher Education. Astra Salvensis 2018, 6, 691-698.

7. Arifin, S.; Ikhfan, H. Assessing soft skills of undergraduate students: Framework for improving competitiveness, innovation and competence of higher education graduates. Stud. Humanit. 2018, 1, 4.

8. Ricchiardi, P.; Emanuel, F. Soft skill assessment in higher education. J. Educ. Cult. Psychol. Stud. 2018, 18, 21-53. [CrossRef]

9. Kasimati, A.; Mysirlaki, S.; Bouta, H.; Paraskeva, F. Ubiquitous game-based learning in higher education: A framework towards the effective integration of game-based learning in higher education using emerging ubiquitous technologies. In Gamification: Concepts, Methodologies, Tools, and Applications; IGI Global: Hershey, PA, USA, 2015; pp. 1015-1039.

10. Koehler, M.; Mishra, P. What is technological pedagogical content knowledge (TPACK)? CITE 2009, 9, 60-70. [CrossRef]

11. Portela, F. A new and interactive teaching approach with gamification for motivating students in computer science classrooms. In Proceedings of the ICPEC 2020-International Computer Programming Education Conference, Argivai, Portugal, 23-24 April 2020; pp. 19:1-19:9. [CrossRef]

12. Partenie, C. The bologna process: Between past reforms and the innovative Future. In Proceedings of the International Multidisciplinary Scientific Conferences on Social Sciences and Arts, Albena, Bulgaria, 2-7 September 2014.

13. Tudor, I. Learner-Centredness as Language Education; Cambridge University Press: Cambridge, UK, 1996.

14. WÄCHTER, B. The Bologna Process: Developments and prospects. Eur. J. Educ. 2004, 39, 265-273. [CrossRef]

15. Dziuban, C.; Graham, C.R.; Moskal, P.D.; Norberg, A.; Sicilia, N. Blended learning: The new normal and emerging technologies. Int. J. Educ. Technol. High. Educ. 2018, 15, 3. [CrossRef]

16. Garrison, D.R.; Kanuka, H. Blended learning: Uncovering its transformative potential in higher education. Internet High. Educ. 2004, 7, 95-105. [CrossRef]

17. Hrastinski, S. What do we mean by blended learning? TechTrends 2019, 63, 564-569. [CrossRef] 
18. Allen, I.E.; Seaman, J.; Garrett, R. Blending in: The Extent and Promise of Blended Education in the United States; Sloan Consortium: Newburyport, MA, USA, 2007.

19. Caner, M. The definition of blended learning in higher education. In Blended Learning Environments for Adults: Evaluations and Frameworks; IGI Global: Hershey, PA, USA, 2012; pp. 19-34.

20. Miguel Silva, D.F.; Portela, F. ioEduc-Bring your own device to the classroom. In Proceedings of the ICPEC 2020-International Computer Programming Education Conference, Argivai, Portugal, 23-24 April 2020; pp. 23:1-23:9. [CrossRef]

21. Maia, A.; Portela, F.; Santos, M.F. Web Intelligence in Higher Education: A Study on the Usage of Business Intelligence Techniques in Education. In Proceedings of the 2018 6th International Conference on Future Internet of Things and Cloud Workshops (FiCloudW), Barcelona, Spain, 6-8 August 2018; pp. 176-181. [CrossRef]

22. Davis, C. Flipped or inverted learning: Strategies for course design. In Enhancing Instruction with Visual Media: Utilizing Video and Lecture Capture; IGI Global: Hershey, PA, USA, 2013; p. 25.

23. WordsWorthLearning-Flipped Classroom, Category: Reading \& Spelling, 2016. WordsWorthLearning. Available online: https://wordsworthlearning.com/blog/wordsworthlearning-flipped-classroom/ (accessed on 1 October 2020).

24. Strayer, J. How learning in an inverted classroom influences cooperation, innovation and task orientation. In Learning Environments Research; Springer: Berlin, Gemany, 2012; p. 16.

25. Kapp, K. The Gamification of Learning and Instruction: Game-Based Methods and Strategies for Training and Education; John Wiley \& Sons: Hoboken, NJ, USA, 2012.

26. Giannakas, F.; Kambourakis, G.; Papasalouros, A.; Gritzalis, S. A critical review of 13 years of mobile game-based learning. Educ. Technol. Res. Dev. 2018, 66, 341-384. [CrossRef]

27. Li, M.C.; Tsai, C.C. Game-based learning in science education: A review of relevant research. J. Sci. Educ. Technol. 2013, 22, 877-898. [CrossRef]

28. Herring, M.C.; Koehler, M.J.; Mishra, P. Handbook of Technological Pedagogical Content Knowledge (TPACK) for Educators; Routledge: Abingdon-on-Thames, UK, 2016.

29. Glavin, C. Project-Based Learning, 2019. K12academics. Available online: https://www.k12academics.com/ Educational\%20Practices/project-based-learning (accessed on 1 October 2020).

30. Bell, S. Project-based learning for the 21st century: Skills for the future. Clear. House 2010, 83, $39-43$.

31. Larmer, J.; Mergendoller, J.R.; Boss, S. Gold standard PBL: Essential project design elements. Buck Inst. Educ. 2015, 1-4.

32. Barbosa, T.J.; Barbosa, M.J. Zoom: An Innovative Solution For The Live-Online Virtual Classroom. HETS Online J. 2019, 9, 2.

33. Ross, S.M. Slack it to me: Complementing LMS with student-centric communications for the millennial/post-millennial student. J. Mark. Educ. 2019, 41, 91-108. [CrossRef]

34. Wang, A.I.; Tahir, R. The effect of using Kahoot! for learning-A literature review. Comput. Educ. 2020, 149, 103818. [CrossRef]

35. Fernandes, G.; Portela, F.; Santos, M.F. PWA and Pervasive Information System-A New Era. In Advances in Intelligent Systems and Computing (WorldCist 2020-PIS Workshop); Springer: Berlin, Germany, 2020; pp. 334-343. [CrossRef]

36. AWS. AWS Cloud9. 2020. Available online: https://aws.amazon.com/cloud9/ (accessed on 1 October 2020).

37. Robinson, J. Likert Scale. In Encyclopedia of Quality of Life and Well-Being Research; Splinger: Berlin, Germany, 2014.

Publisher's Note: MDPI stays neutral with regard to jurisdictional claims in published maps and institutional affiliations.

(C) 2020 by the author. Licensee MDPI, Basel, Switzerland. This article is an open access article distributed under the terms and conditions of the Creative Commons Attribution (CC BY) license (http://creativecommons.org/licenses/by/4.0/). 